\title{
Memorial for Carina Henriksson
}

\author{
Tone Saevi NLA University College, School of Education \\ Bergen, Norway \\ tone.saevi@nla.no
}

As many readers may know, Carina Henriksson passed away on May 21, 2018 at the age of 62. Carina was born and lived most of her life in Sweden. She is buried near Ronneby where she and her family had a house close to the sea. Before returning to Sweden a year before she died, Carina lived with her family in Singapore and Australia and was connected to Brunei University, Australia Catholic University, and Flinders University, respectively. Carina was one of the founders of Phenomenology \& Practice in 2007, and she was the main editor from 2007 to 2010. She steadily led the journal during the first tenuous years combining resoluteness with a great sense of humor and wit. Carina was an excellent phenomenological writer and seer. Her unique and wonderful writing style speaks through a passage from an article published in Phenomenology \& Practice in 2009:

Our memory is, however, more than a mental force that enables us to recall personal experiences. The memory is, in fact, what 'makes shared experience possible '(Kuhns, 1970, p. 107). Recollections, as Socrates describes them, might turn into memories by the sight of something that we assocate with something else - for example, people, objects, places, feelings - and help us open up the intersubjective space of shared experience:

Sometimes during the evening one of the children found an old photo album and started to ask questions about people who she did not recognize in the photos. My sister-in-law walked over to help identify people. Suddenly she exclaimed: "Look! The old blue bucket!" Suddenly the child with the photo album found herself surrounded by adult relatives. "We used to carry the fish from the boat to Aunt Amelia's house in it. Remember how it reeked of fish?"

"Oh, yes, we kept it in the garden shed because of the smell!"

"Aunt Amelia really hated when we brought her eels, especially if they were small!"

"Still, her pickled eel was one of the best in the village..." More and more relatives gathered around the table to join in the conversation. "Didn't we use that bucket when we bricked your garage, Andy?"

"Yes, we did! I had forgotten that. Remember when Marge brought us coffee and you fell off the ladder when you tried to reach the mug? God how we laughed!"

"Who bought Aunt Amelia's house when she died?" 


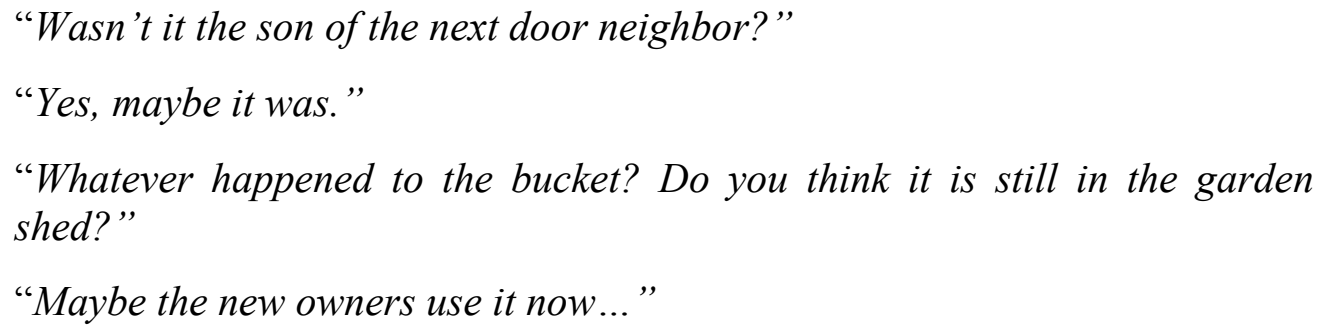

The blue bucket was not just a conversation piece; it became a mediator of past events and it evoked memories of people, places, and moods. The Past was no longer the past that had been, but a past alive in the Now. Undoubtedly, several lived experiences were recollected and turned into memories that evening. Perhaps these lived experiences were also told, shared and interpreted. As researchers we need to tread lightly both when we borrow other peoples' lived experiences and when we set up to write and interpret these experiences. In addition, as the different steps of the reduction urges us, we need to keep a close eye on our own lived experiences of the phenomenon under investigation. We too have bodies with their own knowledge and memories, bodies which may lead us astray when we try to describe and understand possible meanings of the phenomenon. If memory and recollections are etymologically connected to the act of 'committing to writing' then the mere act of writing down the memory would result in a 'Eureka!'. But, to catch that which 'shines forth' in a phenomenon with words is, at times, as impossible as trying to cath a sun beam. We may find that we 'see the words fly about the room in all directions' (Abrams, 1953, p. 216). Yet, we hods with van Manen (1997b) that writing is the method of coming to understand the meaning of lived experience (Henriksson \& Saevi, 2009, p. 45-46).

Carina has written insightful reflective phenomenological texts, like the above excerpt, and also in innovative ways brought nuances to phenomenological methodology. In her doctoral dissertation, she starts with the term anecdote, a narrative or story that has some kind of secrecy to it, and of which van Manen (1990, p. 116) says: "can be understood as a methodological device in human science to make comprehensible some notion that easily eludes us." An anecdote is by Carina considered a full story told by the informant, with little or no need for editing. In contrast, she sees the need for inventing the notions conecdote and synecdote in cases where there is a need to edit and reconstruct transcribed interviews into coherent stories of lived experience, or to amalgamate written lived experience descriptions from the informants with interview material from them (Henriksson, 2004, p. 23).

From my view - as Carina's friend and close collaborator for many years - still another aspect is even more significant to her being, thinking, and writing; her heart for and concern with vulnerable young people who fall short for so many reasons in life and school. Her book Living away from blessings (2004), is a strong phenomenological analysis of how students in the classroom live with disappointment, non-recognition, loneliness, shame, and a sense of worthlessness. She ends her book like this, citing Heidegger (1971):

If, at the end of the day, behavioral failure functions as a barrier, which simultaneously denies educational success and advances failure, we cannot regard the two as disparate sides of a coin. It is the coin.

Forests spread

Brooks plunge

Rocks persist

Mist diffuses

Meadows wait

Springs well 
Winds dwell

Blessing muses

(p. 14)

Behavioral failure is experiential school failure. School failure is to experience human failure in the eyes of the Other and in the eyes of Self. School failure forces children to live away from blessings. The home they are trapped in, their Befindlichkeit, offers no musing, no deliberation. (Henriksson, 2004, p. 181)

It is with sadness for the loss of Carina Henriksson that I share these reflections with our readers. I am also, however, grateful to her for being such a good colleague and for her uplifting friendship.

\section{References}

Henriksson, C. (2004). Living away from blessings. School failure as lived experience. Växjö: Växjö University Press.

Henriksson, C. \& Saevi, T. (2009). An event in sound. Considerations on the ethicalaestetical traits of the hermeneutical phenomenological text. Phenomenology \& Practice, 3(1), 35-58. 